\title{
Virtual clinics in the present - a predictor for the future?
}

\author{
Authors: Tina Parish, ${ }^{\mathrm{A}}$ Maathu Ratnaraj ${ }^{\mathrm{A}}$ and Tazeen J Ahmed $^{\mathrm{B}}$
}

\section{Introduction}

There is great interest in non-face-to-face (F2F), internet or app based outpatient interaction at the moment. As these become established, we look at the non-F2F appointments already happening in telephone and virtual clinics in a busy urban rheumatology department. Here we look at the type of diagnoses dealt with in a non-F2F environment and potential outcomes from these non-F2F appointments.

\section{Materials and methods}

Data was collected from electronic (Cerner) patient records on 240 patients who had a virtual appointment in May 2018. The data was analysed using MS Excel 2010.

\section{Results}

Two hundred and forty patients had virtual appointments in 1 month; 121 (50.4\%) were via telephone and 119 (49.6\%) via patient letter; 34 (14.1\%) patients had multiple virtual/telephone appointments; 129 (54\%) were carried out by consultants, 78 (32\%) by nurses and $33(14 \%)$ by registrars; $37 \%$ had rheumatoid arthritis; 32 (13\%) appointments lead to a prescription. Virtual appointments produced 44 referrals, including 18 to another specialty, 16 to physiotherapy and the rest to hand therapy or podiatry. Most patients had an F2F appointment before and after their virtual appointment in May 2018, one patient had died before having a second F2F appointment and 13 (5\%) were discharged from their virtual appointment.

\section{Conclusion}

Consultants undertook the bulk of virtual clinics, and these appointments resulted in the majority of referrals and prescriptions. Virtual appointments reduce the waiting times for contact with a healthcare professional between appointments. Many patients had several virtual appointments between F2F appointments and this cohort may benefit from more scrutiny. Current technology already improves communication and leads to significant changes in patient care without requiring F2F appointments. Internet based and app based interaction should face the same scrutiny.

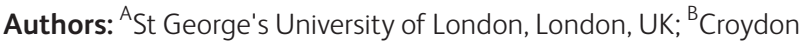
University Hospital, Croydon, UK

$\begin{array}{ll}\begin{array}{l}\text { Table 1. The mean number of days between each } \\ \text { type of appointment }\end{array} & \begin{array}{l}\text { Mean number } \\ \text { of days between } \\ \text { appointments }\end{array} \\ & 44 \\ \begin{array}{ll}\text { From first face-to-face to virtual appointment } \\ \text { From virtual to second face-to-face }\end{array} & 53 \\ \begin{array}{l}\text { appointment } \\ \text { From first face-to-face to second face-to-face } \\ \text { appointment }\end{array} & 94\end{array}$

